\title{
Permanencias y transformaciones de los estilos parentales en la crianza de personas con discapacidad
}

\author{
Permanence and transformations of parental styles in the raising \\ of people with disabilities
}

\author{
Dora Manjarrés-Carrizalez $z^{1} \underline{\mathrm{ORCID}}$, Christian Hederich-Martínez ${ }^{2} \underline{\mathrm{ORCID}}$ \\ Universidad Pedagógica Nacional \\ Colombia
}

Fecha correspondencia:

Recibido: agosto 1 de 2019.

Aceptado: marzo 19 de 2020.

Forma de citar:

Manjarrés-Carrizalez, D., \& Hederich-

Martínez, C. (2020). Permanencias

y transformaciones de los estilos

parentales en la crianza de personas

con discapacidad. Rev. CES Psico,

13(2), 61-84.

Open access

(c) Copyright

Licencia creative commons

Ética de publicaciones

Revisión por pares

Gestión por Open Journal System

DOl: http://dx.doi.org/10.21615/

cesp. 13.2 .5

ISSN: 2011-3080

Sobre los autores:

1. Profesora asociada de la

Universidad Pedagógica Nacional.

Candidata a Doctora en Educación,

Universidad Pedagógica Nacional.

Comparte

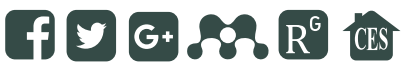

\section{Resumen}

Se presentan los resultados de un estudio que tiene como objetivo establecer las permanencias y las transformaciones de los estilos parentales en la crianza de personas con discapacidad durante un periodo de siete años e identificar las posibles explicaciones que las motivan. El estudio toma como base el Modelo Estilos Parentales en la Discapacidad -MEPD- (Manjarrés \& Hederich, 2018) que identifica y describe las formas como los padres educan a sus hijos. Es un estudio longitudinal de casos múltiples que hace seguimiento al estilo parental en dos momentos del proceso de crianza de 18 personas con discapacidad (2011 y 2018). Los resultados permiten identificar, siete años después, la presencia de tres de los cuatro estilos parentales planteados por el MEPD: impulsador-reflexivo, dominador-inflexible y dominado-complaciente y la ausencia del estilo dominado-distante. Se evidencia la permanencia del estilo parental original en la mitad de los casos, en los que se puede establecer la funcionalidad de éste. Por su parte, las transformaciones del estilo parental muestran dos posibles tránsitos: uno, de carácter positivo, más frecuente, hacia estilos más favorecedores del desarrollo de la autonomía del hijo; el otro, negativo, hacia estilos que favorecen una mayor dependencia continuada. Mientras que las transformaciones positivas son motivadas por el reconocimiento paulatino de la capacidad del hijo, las negativas están asociadas con la pérdida objetiva de la capacidad del hijo y de su posibilidad de relacionarse.

Palabras claves: Discapacidad, Estilos Parentales, Trayectoria Vital, Crianza.

\section{Abstract}

This study aims at establishing the permanence and transformations of parenting styles in the upbringing of disable people around age of seven and identifying the possible explanations that motivate them. The study is based on the Parental Styles in Disability Model -MEPD- (Manjarrés \& Hederich, 2018) that identifies and describes the ways in which parents educate their children. It is a longitudinal study of multiple cases that tracks the parental raising style of 18 participants with disabilities, at two stages of their lifetime (2011 and 2018). The results allow us to identify, seven years later, 
Magister en Desarrollo Educativo y Social, Universidad Pedagógica Nacional y Centro Internacional en Educación y Desarrollo Humano (CINDE). Especialista en Educación Especial con Énfasis en Comunicación Aumentativa y Alternativa. Grupo de investigación Familia y Escuela.

\section{Profesor titular de la} Universidad Pedagógica Nacional. Doctor en Psicología de la Universidad Autónoma de Barcelona. Magíster en Desarrollo Educativo y Social, Universidad Pedagógica Nacional y Centro Internacional en Educación y Desarrollo Humano (CINDE). Matemático, Pontificia Universidad Javeriana. Líder del grupo de Investigación Estilos Cognitivos. the presence of three of the four parental styles proposed by the MEPD: driving-reflexive, dominating-inflexible and dominated-complacent and the absence of the dominated-distant style. The permanence of the original parental style is evident in half of the cases, in which its functionality can be established. On the other hand, the transformations of the parental style show two possible transits: one of positive nature, the most common, points towards more favorable styles of the development of the child's autonomy; the other, negative, points towards styles that favor a greater continued dependency. While the positive transformations are motivated by the gradual recognition of the child's capacity, the negative ones are associated with the objective loss of the child's capacity and the possibility of relating.

Keywords: Disability, Parental Education Styles, Parenting Style, Vital Trajectory, Raising.

\section{Introducción}

El reconocimiento del papel fundamental que cumplen los padres, madres o quienes ejercen la función parental en el desarrollo personal y social de los hijos, conlleva al planteamiento de estudios que aborden como objeto las relaciones parentofiliales (Cámara \& López, 2014; Isaza \& Henao, 2012; Mestre, 2014; Montoya, Prado, Villanueva, \& González, 2016; Murillo, Priegue, \& Cambeiro, 2015; Pinto, Sangüesa, \& Silva, 2012). Estos estudios buscan ampliar la comprensión de las distintas formas de educación parental y plantear desde allí estrategias de acompañamiento y fortalecimiento a las actividades de crianza de las familias.

Los estilos parentales representan los modos consistentes de actuar de los padres frente a la crianza de sus hijos y la forma como los educan y desarrollan su función paterna y materna. Estos son definidos por Coloma (1993) como "esquemas prácticos que reducen las múltiples y minuciosas prácticas educativas paternas a unas pocas dimensiones que, cruzadas entre sí en diferentes combinaciones, dan lugar a diversos tipos habituales de educación parental" (p.48). Por su parte, Aroca y Cánovas (2012) señalan que el estilo parental intenta crear unas coordenadas de regulación dentro de las que se enmarcan y describen estrategias y mecanismos de socialización y educación que los padres ejercen sobre los hijos, en términos de creencias, valores y comportamientos que pretenden influir en su desarrollo.

Los trabajos de Diana Baumrind, pionera en el estudio de los estilos parentales de crianza, han documentado la influencia de éstos en el desarrollo de los niños. A través de esta línea de estudios, ha mostrado cómo los estilos parentales favorecen en mayor o menor forma los procesos de desarrollo personal, social, la madurez y la autonomía de los hijos (Baumrind, 1971, 1991, 1996, 2005).

Para Torío, Peña y Rodríguez (2008), los estilos parentales con frecuencia varían según la etapa de desarrollo del niño. Así, las formas que utilizan los padres, madres, familiares o quienes ejercen la función parental para educar a los hijos, pueden transformarse y ser influenciadas por diversas condiciones personales y contextuales ocurridas durante la trayectoria vital. Por lo tanto, analizar los estilos parentales y sus transformaciones, en el marco de la realidad de cada familia y en el contexto del momento evolutivo en que se encuentra el hijo e identificar tendencias globales en el comportamiento parental, permitirá alcanzar mayor comprensión frente a las dimensiones involucradas en la interacción parentofilial. 
Pág 63

Estudios como los de Acosta, Toro y Guerrero (2015), por ejemplo, muestran cómo los estilos parentales de crianza influyen en el desarrollo de la seguridad, la autoconfianza, la autoestima, la autonomía y la formación de valores de los niños con necesidades educativas especiales. Por su parte, Mazzucchelli et al. (2018), relacionan el desarrollo emocional y comportamental del hijo con discapacidad con el funcionamiento familiar y con las prácticas educativas de los padres.
Cuando se trata de la crianza de hijos con discapacidad, es particularmente importante que los padres brinden suficientes oportunidades y estrategias para que sus hijos puedan alcanzar su pleno desarrollo personal, fortalezcan sus relaciones interpersonales y potencien procesos de autonomía e inclusión social (Aguirre \& Castro, 2007). Al respecto, existe una nutrida línea de trabajos centrados en la influencia del estilo parental en el desarrollo personal y social de las personas con discapacidad. Estudios como los de Acosta, Toro y Guerrero (2015), por ejemplo, muestran cómo los estilos parentales de crianza influyen en el desarrollo de la seguridad, la autoconfianza, la autoestima, la autonomía y la formación de valores de los niños con necesidades educativas especiales. Por su parte, Mazzucchelli et al. (2018), relacionan el desarrollo emocional y comportamental del hijo con discapacidad con el funcionamiento familiar y con las prácticas educativas de los padres. En el estudio de población con discapacidades específicas, Rapin (2007) profundiza en el análisis de la influencia de los padres en la calidad de vida de niños con parálisis cerebral y concluye que la forma como los padres enfrentan la discapacidad trae consecuencias en las prácticas de crianza. De forma similar, Rodríguez y Guerrero, (2012) señalan la influencia de las formas de educar de los padres en el desarrollo de la independencia de niños con discapacidad motora.

Otros estudios identifican y documentan diversas condiciones y situaciones que experimentan los padres a lo largo de la trayectoria vital de los hijos con discapacidad, que exigen cambios y ajustes al sistema familiar y pueden motivar transformaciones en los estilos de crianza. Entre ellas, vale la pena mencionar el progresivo aumento del estrés parental durante el proceso de crianza (Woolfson \& Grant, 2006); las modificaciones en los juicios de valor relacionados con conceptos de normalidad y anormalidad (Ortega, Salquero, \& Garrido, 2007); el cambio del significado de la paternidad, producto de la experiencia propia del manejo de la discapacidad (Zuliani, Bastidas, Ariza, \& Giraldo, 2015); las aspiraciones educativas y sociales de los padres, la concepción de su rol y el sentimiento de vergüenza o aceptación de la discapacidad (Yotyodying \& Wild, 2016); las estrategias de afrontamiento parental de los aspectos desconocidos de la discapacidad (Díaz \& Mejía, 2015) y la esperanza, como predictor y promotor del bienestar parental (Shenaar-Golan, 2015), entre otras.

Para el estudio y caracterización de los estilos parentales en los procesos de crianza de personas con discapacidad, previamente hemos propuesto un modelo descriptivo denominado "Modelo Estilos Parentales en la Discapacidad" -MEPD- (Manjarrés \& Hederich, 2018). En el MEPD planteamos que, si bien el estilo parental se configura en contextos familiares específicos, una vez éste se consolida en la familia tiende a mostrar cierta permanencia en la medida en que incorpora, como elementos estructurales de las relaciones parentofiliales, tres procesos relativamente estables involucrados en la crianza: las creencias, las pautas y las prácticas de crianza. Describiremos brevemente el modelo.

Las creencias, se refieren a las visiones o formas parentales de percibir la discapacidad del hijo a las cuales subyace una concepción de niño (hijo) y una concepción de adulto (padre) que orientan el modo de educar. Las pautas, se centran en la naturaleza de las normas definidas, los valores enfatizados y los mecanismos motivacionales puestos en juego por el padre, madre o quien ejerce la función parental; aspectos que permiten evidenciar el canon y el orden normativo que impera en la relación. Las prácticas son las acciones parentales ejercidas en la interacción, que para el modelo se relacionan principalmente con los niveles de control, afecto, disciplina, responsabilidad, placer percibido y apoyo. Según el modelo, las creencias son el núcleo, el centro 
de la estructura relacional que expresa lo más interno de quien ejerce la función parental y así, lo más complejo de transformar; y son las que orientan las pautas y determinan las prácticas.

De acuerdo con las combinaciones de estos aspectos estructurales, el MEPD plantea la configuración de cuatro estilos parentales, que se han denominado impulsador-reflexivo, dominador-inflexible, dominado-complaciente y dominado-distante. La Tabla 1 muestra las características generales de cada uno de estos estilos.

Tabla 1. Estilos parentales planteados por el MEPD

\begin{tabular}{|c|c|c|c|c|c|}
\hline \multirow[b]{2}{*}{ Procesos } & \multirow[b]{2}{*}{ Indicadores } & \multicolumn{4}{|c|}{ Estilos parentales } \\
\hline & & $\begin{array}{l}\text { Impulsador - } \\
\text { reflexivo }\end{array}$ & $\begin{array}{l}\text { Dominador- } \\
\text { inflexible }\end{array}$ & $\begin{array}{c}\text { Dominado - } \\
\text { Complaciente }\end{array}$ & $\begin{array}{l}\text { Dominado- } \\
\text { distante }\end{array}$ \\
\hline \multirow{3}{*}{ Creencias } & $\begin{array}{l}\text { Visión de la } \\
\text { discapacidad }\end{array}$ & $\begin{array}{l}\text { Social } \\
\text { Normalizadora- } \\
\text { asistencialista }\end{array}$ & $\begin{array}{l}\text { Médico- } \\
\text { reparadora }\end{array}$ & $\begin{array}{l}\text { Sacralizada- } \\
\text { mágica. } \\
\text { Médico- } \\
\text { reparadora. }\end{array}$ & $\begin{array}{l}\text { Médico- } \\
\text { reparadora }\end{array}$ \\
\hline & $\begin{array}{l}\text { Concepción de } \\
\text { niño }\end{array}$ & $\begin{array}{l}\text { Hábil- } \\
\text { enseñante }\end{array}$ & $\begin{array}{l}\text { Sometido- } \\
\text { dominado }\end{array}$ & $\begin{array}{l}\text { Impulsivo- } \\
\text { dominante }\end{array}$ & $\begin{array}{l}\text { Lejano- } \\
\text { inalcanzable }\end{array}$ \\
\hline & $\begin{array}{l}\text { Concepción de } \\
\text { adulto }\end{array}$ & $\begin{array}{l}\text { Impulsador } \\
\text {-orientador }\end{array}$ & $\begin{array}{l}\text { Dominador- } \\
\text { sapiente }\end{array}$ & $\begin{array}{l}\text { Dominado- } \\
\text { sometido }\end{array}$ & $\begin{array}{l}\text { Incapaz- } \\
\text { ausente }\end{array}$ \\
\hline \multirow{3}{*}{ Pautas } & $\begin{array}{l}\text { Naturaleza de } \\
\text { las normas }\end{array}$ & Negociadas & Inflexibles & $\begin{array}{l}\text { Mínimas } \\
\text { básicas }\end{array}$ & Sin normas \\
\hline & $\begin{array}{l}\text { Valores } \\
\text { enfatizados }\end{array}$ & $\begin{array}{l}\text { Capacidad } \\
\text { propia }\end{array}$ & Obediencia & $\begin{array}{l}\text { Goce del } \\
\text { momento }\end{array}$ & Ninguno \\
\hline & $\begin{array}{l}\text { Motivación } \\
\text { promovida }\end{array}$ & Intrínseca & Extrínseca & Extrínseca & Desmotivación \\
\hline \multirow{6}{*}{ Prácticas } & $\begin{array}{l}\text { Nivel de control } \\
\text { ejercido }\end{array}$ & Mucho control & Mucho control & Poco control & Ningún control \\
\hline & $\begin{array}{l}\text { Nivel de afecto } \\
\text { expresado al hijo }\end{array}$ & Mucho afecto & Poco afecto & Mucho afecto & Poco afecto \\
\hline & $\begin{array}{l}\text { Disciplina } \\
\text { impartida }\end{array}$ & $\begin{array}{l}\text { Acción- } \\
\text { consecuencia- } \\
\text { reflexión }\end{array}$ & $\begin{array}{l}\text { Acción- } \\
\text { consecuencia }\end{array}$ & $\begin{array}{l}\text { Acción- no } \\
\text { consecuencia }\end{array}$ & Ninguna \\
\hline & $\begin{array}{l}\text { Nivel de } \\
\text { responsabilidad } \\
\text { asignada al hijo }\end{array}$ & Mucha & Mucha & Poca o ninguna & Ninguna \\
\hline & $\begin{array}{l}\text { Énfasis en } \\
\text { actividades } \\
\text { lúdicas }\end{array}$ & Mucho & Poco & Mucho & Ninguno \\
\hline & $\begin{array}{l}\text { Implicación en } \\
\text { el desarrollo del } \\
\text { hijo }\end{array}$ & $\begin{array}{l}\text { Alta implicación. } \\
\text { Permite espacio } \\
\text { personal }\end{array}$ & $\begin{array}{l}\text { Alta } \\
\text { implicación. } \\
\text { No permite } \\
\text { esp. personal }\end{array}$ & $\begin{array}{l}\text { Alta } \\
\text { implicación. No } \\
\text { permite esp. } \\
\text { personal }\end{array}$ & $\begin{array}{l}\text { Hay } \\
\text { presencia sin } \\
\text { implicación. }\end{array}$ \\
\hline
\end{tabular}

Fuente: Adaptación de Manjarrés \& Hederich, 2018.

El estilo parental "impulsador-reflexivo" es caracterizado por un padre, madre o quien ejerce la función parental que concibe al hijo con discapacidad como una persona hábil, y por consiguiente, se identifica a sí mismo como adulto impulsador y orientador de dichas habilidades. Está situado en una visión social de la discapacidad que la concibe como el resultado de la interacción entre la condición particular del hijo y las oportunidades que el entorno le brinda para el aprendizaje y la participación. 
Los valores que enfatiza se centran en el desarrollo de las capacidades del hijo. Las normas que imparte son negociadas y la motivación que promueve es intrínseca, enfatizando el deseo de superación y el logro de objetivos y metas personales. Brinda apoyo y se implica en el desarrollo del hijo, permitiéndole su espacio personal. La disciplina que imparte se centra en que las acciones tienen consecuencias, siempre mediadas por la reflexión. Le delega responsabilidad al hijo, en consonancia con el reconocimiento de sus habilidades, y también le permite y promueve diversos espacios recreativos. Le expresa mucho afecto al hijo y, a la vez, ejerce mucho control.

Por su parte, el estilo "dominador-inflexible" se caracteriza por un padre, madre o quien ejerce la función parental centrado en una visión médico-reparadora de la discapacidad, en la que ésta se entiende como un problema de salud que debe ser reparado y el mismo se concibe como estricto supervisor de la cura. Le impone al hijo normas rígidas, promueve en éste una motivación extrínseca y enfatiza en valores relacionados con la obediencia, tales como la lealtad, el respeto y la sumisión. Está muy implicado en todos los asuntos relacionados con el desarrollo del hijo, hasta el punto de no permitirle espacio personal, y le expresa poco afecto. La disciplina que imparte se caracteriza porque las acciones siempre tienen consecuencias fijas. Le permite al hijo pocos espacios para el disfrute y la recreación y ejerce mucho control en las actividades que realiza.

El estilo parental "dominado-complaciente" se caracteriza por un padre, madre o quien ejerce la función parental que, al igual que el anterior, mantiene una visión médico-reparadora combinada con una visión sacralizada-mágica desde la que la discapacidad se entiende como una consecuencia de culpas pasadas y, en esa medida él mismo se concibe como un adulto dominado y sometido ante las exigencias y particularidades propias de la discapacidad del hijo. Esta perspectiva da al hijo un rol dominante, y, en consecuencia, en este estilo parental hay ausencia de normas y los valores promovidos enfatizan la felicidad inmediata del hijo. El padre aquí ejerce poco control; las acciones del hijo no tienen consecuencias, y se le asigna poca o ninguna responsabilidad, otorgándole muchos espacios para la dispersión y el disfrute. Tiene un alto nivel de implicación en el desarrollo del hijo, sin permitirle espacio personal. De esta forma, la autorrealización parental se sacrifica por la atención exclusiva al hijo, generalmente relacionada con satisfacer deseos y requerimientos inmediatos.

Finalmente, el estilo parental "dominado-distante" es caracterizado por un padre, madre o quien ejerce la función parental que concibe al hijo con discapacidad como alguien lejano e inalcanzable a su conocimiento y a su margen de acción, lo que lo lleva a considerarse como un adulto incapaz y ausente del proceso de desarrollo del hijo. La visión de discapacidad que impera en este estilo es la médico-reparadora, si bien, a diferencia de los anteriores, en este caso el cuidador cree que no puede ayudar y, en consecuencia, delega todos los cuidados, no impone normas ni enfatiza la formación de valores. En este estilo el padre hace presencia, pero expresa poco afecto, no se implica en el desarrollo del hijo con discapacidad y no ejerce ningún control.

Según el MEPD, el criterio que permite distinguir los efectos de estos cuatro estilos parentales es el de la ganancia o pérdida de la autonomía. La autonomía, de acuerdo con Vived (2011), "es la capacidad que tiene una persona para desarrollar una vida lo más satisfactoria e independiente posible en los entornos habituales de la comunidad" (p. 27). De esta forma, la autonomía se va construyendo y fortaleciendo a través 
Teniendo como base el Modelo Estilos Parentales en la Discapacidad -MEPD, su marco estructural, la configuración de los estilos parentales que propone y su relación con los procesos de desarrollo de la autonomía del hijo, se plantea el presente estudio con el objetivo de establecer las permanencias y transformaciones del estilo parental en la crianza de personas con discapacidad e identificar posibles explicaciones. de las diferentes etapas de la trayectoria vital, de acuerdo con las oportunidades que se brinden en el proceso de desarrollo, de exploración, interacción y apropiación del entorno y las posibilidades de aprendizaje y participación. Así, el MEPD permite ubicar los estilos parentales en el espectro, de menor a mayor favorecimiento de la autonomía del hijo; de manera que los estilos dominado-distante y dominado-complaciente, se encuentran en el extremo que mejor predice la dependencia continuada y, por ello, es menos favorable al desarrollo de la autonomía; el estilo dominador-inflexible se encuentra en un punto medio y el estilo impulsador-reflexivo se encuentra en el extremo que más favorece el desarrollo de la autonomía.

Teniendo como base el MEPD, su marco estructural, la configuración de los estilos parentales que propone y su relación con los procesos de desarrollo de la autonomía del hijo, se plantea el presente estudio con el objetivo de establecer las permanencias y transformaciones del estilo parental en la crianza de personas con discapacidad e identificar posibles explicaciones. Para ello, se hace un seguimiento a los procesos de crianza de familias con personas con discapacidad para caracterizar sus estilos parentales en dos momentos separados por siete años. Se parte de lo planteado por el MEPD que propone que el estilo parental tiende a permanecer durante el proceso de crianza, y, en caso de transformarse, el cambio tiende a hacerse en función del logro de una mayor autonomía por parte del hijo.

Se busca aportar a la comprensión de los estilos parentales en la crianza de hijos con discapacidad por medio del estudio de su permanencia o sus transformaciones en la familia durante el ciclo vital del hijo. Esto solo puede ser examinado mediante un estudio longitudinal que realice un seguimiento a los procesos de crianza en momentos diferenciados. Por las dificultades metodológicas que entrañan, este tipo de estudios son escasos, lo que ha conducido a describir la crianza en momentos puntuales del desarrollo de las personas con discapacidad. Así, los resultados permitirán explorar los límites y las posibilidades de las transformaciones en el estilo parental en la crianza de esta población e identificar situaciones que exigen a los padres, madres o quienes ejercen la función parental, permanecer, moverse o transitar en diferentes creencias, pautas y prácticas de crianza.

\section{Metodología}

\section{Diseño}

Este es un estudio longitudinal de casos múltiples que realiza un análisis de naturaleza descriptiva a los procesos de crianza de hijos con alguna discapacidad por parte de sus padres o cuidadores permanentes. La información analizada fue obtenida en dos momentos separados por un intervalo de siete años. Se realiza entonces la comparación entre la información tomada en el año 2011, con la que se le realizó una primera caracterización del estilo parental, y la tomada en el año 2018, con la que se caracterizó nuevamente. A partir de este análisis se identifican permanencias y transformaciones del estilo parental $y$, a partir de los relatos de algunos padres o cuidadores permanentes, se indaga por las posibles explicaciones de los hallazgos identificados.

\section{Participantes}

En 2011, Manjarrés, León, Martínez y Gaitán, entrevistaron a 219 familias de hijos con discapacidad. En 2018, Manjarrés y Hederich retoman esa información y caracterizan estilo parental de 195 familias participantes en el primer momento (año 2011). En el presente estudio se retomó la información de estas 195 familias y se hizo un primer 
proceso de depuración según los siguientes criterios: 1) los informantes no hubieran estado directamente relacionados con la función parental, o 2) no hubieran tenido la posibilidad de haber convivido con el hijo con discapacidad durante los últimos 7 años. Teniendo en cuenta estos criterios, de las 195 familias iniciales se descartaron 34, por lo que la población a convocar quedó conformada por 147 familias, sobre las cuales se exploró la posibilidad de contacto y su disponibilidad para participar voluntariamente en este segundo momento.

La exploración de la información relacionada con estas 147 familias mostró que, en 84 casos los datos registrados en el año 2011 habían caducado y los informantes ya no vivían en los lugares registrados, haciendo muy difícil su contacto. En otros 40 casos los informantes no contestaron a las llamadas ni los correos enviados, a pesar de haberlos recibido, lo que puede considerarse como una actitud renuente a participar en el estudio. Sólo en dos casos los informantes contestaron, pero indicaron que no tenían interés de participar y en otro caso el hijo había fallecido. Finalmente, solo en 18 familias se encontró la disposición a participar y se logró realizar la entrevista planeada; por tanto, estas 18 familias se constituyen en las unidades de análisis de este estudio y, dado este ejercicio de selección la muestra resultante puede ser considerada como autoseleccionada.

Las familias participantes se encuentran ubicadas en 7 municipios de cuatro departamentos de Colombia: 1 caso en Barrancabermeja (Santander), 7 casos en Cartagena (Bolívar), 7 casos en Chipaque, Tenjo y Bogotá (Cundinamarca) y 3 casos en Rionegro y Carmen del Viboral (Antioquia). En todos los casos los estratos socioeconómicos de las familias son medios o bajos. Las fuentes entrevistadas en los 18 casos analizados fueron 2 padres, 14 madres y 2 miembros de la familia extensa, una abuela y una prima, quienes participan directamente en la crianza de la persona con discapacidad asumiendo parte de la función parental.

Respecto a la discapacidad de los hijos, se presenta en la mayoría de los casos discapacidad cognitiva, con presencia también de discapacidad auditiva, visual, autismo y multiimpedimento. La edad de los hijos con discapacidad al momento de la primera aplicación (2011) osciló entre los 7 y los 23 años ( $M=13.00, D E=4.839$.$) . En$ la Tabla 2, se presenta la caracterización general y detallada.

Tabla 2. Caracterización general de los casos analizados

\begin{tabular}{cccccccc}
\hline No. & Género & $\begin{array}{c}\text { Tipo de } \\
\text { discapacidad }\end{array}$ & Tipo de & Especificación u & Edad & Edad & Fuente \\
\hline Número & Sexo & $\begin{array}{c}\text { entre } \\
\text { los } \\
\text { discapacidad } \\
\text { hijos }\end{array}$ & $\begin{array}{c}\text { Edad } \\
\text { en } \\
\mathbf{2 0 1 1}\end{array}$ & $\begin{array}{c}\text { Edad } \\
\text { en } \\
\mathbf{2 0 1 8}\end{array}$ & Informante \\
\hline Caso 1 & Masculino & Cognitiva & S. Down & $3 / 4$ & $\begin{array}{c}14 \\
\text { años }\end{array}$ & $\begin{array}{c}21 \\
\text { años }\end{array}$ & Padre \\
\hline Caso 2 & Masculino & Cognitiva & & $4 / 4$ & 8 años & $\begin{array}{c}15 \\
\text { años }\end{array}$ & Madre \\
\hline Caso 3 & Masculino & Auditiva & & $1 / 2$ & $\begin{array}{c}20 \\
\text { años }\end{array}$ & $\begin{array}{c}27 \\
\text { años }\end{array}$ & Madre \\
\hline Caso 4 & Masculino & Auditiva & & $3 / 3$ & $\begin{array}{c}23 \\
\text { años }\end{array}$ & $\begin{array}{c}30 \\
\text { años }\end{array}$ & Madre \\
\hline
\end{tabular}




\begin{tabular}{|c|c|c|c|c|c|c|c|}
\hline Número & Sexo & $\begin{array}{c}\text { Tipo de } \\
\text { discapacidad }\end{array}$ & $\begin{array}{l}\text { Especificación u } \\
\text { otras condiciones }\end{array}$ & $\begin{array}{c}\text { Lugar } \\
\text { entre } \\
\text { los } \\
\text { hijos }\end{array}$ & $\begin{array}{c}\text { Edad } \\
\text { en } \\
2011\end{array}$ & $\begin{array}{c}\text { Edad } \\
\text { en } \\
2018\end{array}$ & Informante \\
\hline Caso 5 & Masculino & $\begin{array}{l}\text { Auditiva y } \\
\text { cognitiva }\end{array}$ & & $1 / 1$ & 9 años & $\begin{array}{c}17 \\
\text { años }\end{array}$ & Madre \\
\hline Caso 6 & Masculino & Cognitiva & & $1 / 2$ & $\begin{array}{c}11 \\
\text { años }\end{array}$ & $\begin{array}{c}16 \\
\text { años }\end{array}$ & Madre \\
\hline Caso 7 & Femenino & Cognitiva. & S. Down & $4 / 4$ & $\begin{array}{c}15 \\
\text { años }\end{array}$ & $\begin{array}{c}23 \\
\text { años }\end{array}$ & Madre \\
\hline Caso 8 & Masculino & $\begin{array}{c}\text { Motriz, } \\
\text { cognitiva y } \\
\text { comunicativa }\end{array}$ & & $1 / 2$ & $\begin{array}{c}11 \\
\text { años }\end{array}$ & $\begin{array}{c}18 \\
\text { años }\end{array}$ & Padre \\
\hline Caso 9 & Masculino & Cognitiva & S. Down & $1 / 3$ & $\begin{array}{c}10 \\
\text { años }\end{array}$ & $\begin{array}{c}17 \\
\text { años }\end{array}$ & Abuela \\
\hline Caso 10 & Masculino & Cognitiva & S. Down & $3 / 3$ & $\begin{array}{c}22 \\
\text { años }\end{array}$ & $\begin{array}{c}28 \\
\text { años }\end{array}$ & Madre \\
\hline Caso 11 & Masculino & Cognitiva & S. Down & $2 / 2$ & 9 años & $\begin{array}{c}16 \\
\text { años }\end{array}$ & Madre \\
\hline Caso 12 & Masculino & Cognitiva & S. Down & $2 / 3$ & $\begin{array}{c}12 \\
\text { años }\end{array}$ & $\begin{array}{c}19 \\
\text { años }\end{array}$ & Madre \\
\hline Caso 13 & Femenino & Autismo & $\begin{array}{c}\text { Mucopolisacaridosis } \\
\text { tipo III }\end{array}$ & $2 / 2$ & 8 años & $\begin{array}{c}16 \\
\text { años }\end{array}$ & Madre \\
\hline Caso 14 & Masculino & Cognitiva & & $2 / 4$ & $\begin{array}{c}14 \\
\text { años }\end{array}$ & $\begin{array}{c}22 \\
\text { años }\end{array}$ & Madre \\
\hline Caso 15 & Masculino & Cognitiva & & $3 / 3$ & 14años & $\begin{array}{c}21 \\
\text { años }\end{array}$ & Madre \\
\hline Caso 16 & Femenino & Cognitiva & & $4 / 5$ & 7 años & $\begin{array}{c}14 \\
\text { años }\end{array}$ & Prima \\
\hline Caso 17 & Masculino & $\begin{array}{c}\text { Motriz, } \\
\text { cognitiva y } \\
\text { comunicativa }\end{array}$ & $\begin{array}{c}\text { PC severa con } \\
\text { cuadriparesia } \\
\text { espástica }\end{array}$ & $\begin{array}{l}\text { 2011: } \\
2 / 3 \\
2018: \\
2 / 4\end{array}$ & $\begin{array}{c}10 \\
\text { años }\end{array}$ & $\begin{array}{c}17 \\
\text { años }\end{array}$ & Madre \\
\hline Caso 18 & Masculino & Visual & & $2 / 3$ & $\begin{array}{c}17 \\
\text { años }\end{array}$ & $\begin{array}{c}24 \\
\text { años }\end{array}$ & Madre \\
\hline
\end{tabular}

Fuente: Elaboración propia

\section{Instrumentos}

En 2011, con el fin de identificar dinámicas de crianza de las personas con discapacidad en las familias participantes, se obtuvo información a partir de entrevistas orientadas por tres preguntas abiertas activadoras de relatos (¿cómo fue su crianza?, ¿cómo ha sido la crianza de su hijo con discapacidad?, ¿cuál es el ideal de crianza para una persona con discapacidad?), sobre la base de estos relatos se realizó la primera caracterización del estilo parental. A raíz de los análisis hechos sobre la totalidad de la muestra (195 casos retomados del 2011), en 2018, se diseñó una encuesta con preguntas semiestructuradas que permitió recoger, de forma más puntual, la información para caracterizar el estilo parental. De cualquier forma, se mantuvieron en la encuesta algunas de las preguntas iniciales a fin de obtener narraciones que complementen los resultados sobre el estilo parental. Este instrumento se aplicó en el segundo momento de seguimiento a los procesos de crianza en los 18 casos que conforman la muestra (véase anexo 1). 


\section{Análisis}

Para el procesamiento y análisis de la información, se realizó la caracterización e identificación del estilo parental a través de la codificación y procesamiento univariado y multivariado de la información obtenida en ambos momentos, tomando como base el marco estructural de variables y valores planteados por el MEPD para establecer la configuración del estilo parental (Manjarrés \& Hederich, 2018, p. 191). De allí, se adelantó un ejercicio comparativo de los estilos parentales identificados en los dos momentos para establecer permanencias y transformaciones de los mismos. Finalmente, a partir de narraciones efectuadas por los informantes, se examinan e identifican posibles explicaciones y predictores de las permanencias y transformaciones del estilo parental en la trayectoria vital parentofilial.

\section{Aspectos éticos}

En los dos momentos de recolección de información se siguieron protocolos éticos en los cuales se convocó a los participantes y se les informó los objetivos de la investigación. Los informantes aceptaron participar de forma voluntaria y se les leyó y diligenció el consentimiento informado. Los análisis de la información guardan estricta relación con las expresiones y narraciones de los participantes. El presente estudio cuenta con el aval del Comité de ética de la Universidad Pedagógica Nacional (UPN) y, por tanto, se siguieron los principios para orientar la ética en la investigación UPN relacionados con el respeto por las personas, sus territorios, su dignidad y su diversidad; integridad; responsabilidad social y compromiso con el conocimiento (UPN, Resolución 1642 de 18 diciembre de 2018, artículo 5).

\section{Resultados}

\section{Descripción general}

Respecto a los 18 casos objeto de análisis del presente estudio, en el primer momento de recolección de la información el estilo parental de crianza que predominó fue el dominador-inflexible con 9 casos, seguido del impulsador- reflexivo con 6 casos y finalmente el dominado-complaciente con 3 casos (ver ilustración 2a). El cuarto estilo que incluye el MEPD, denominado dominado-distante, no se identificó en ninguno de los casos seleccionados. En principio, debe mencionarse que, de los 195 casos retomados de 2011, solo 10 respondían a la caracterización estilo parental dominado-distante. La escasa frecuencia de este estilo puede explicarse, en parte, por sus características distintivas, en tanto supone muy poca participación e implicación en la crianza, por lo que se espera que los padres que lo presentan se disponen con menor frecuencia a participar en este tipo de procesos de indagación.

En el segundo momento de seguimiento al proceso de crianza la caracterización de los estilos arrojó un predominio del estilo parental impulsador-reflexivo con 11 casos, seguido del dominador-inflexible con 4 casos y el dominado-complaciente con 3 casos (ver ilustración 2b). Aquí, de nuevo se encuentra ausente el estilo dominado-distante. 


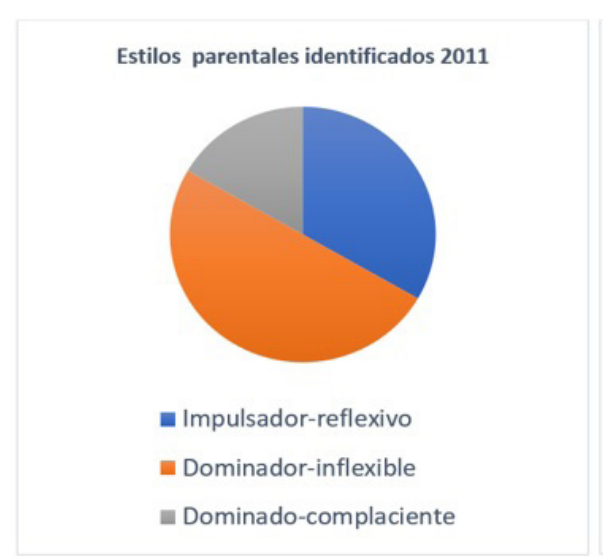

Ilustración 2a. Caracterización EP 2011
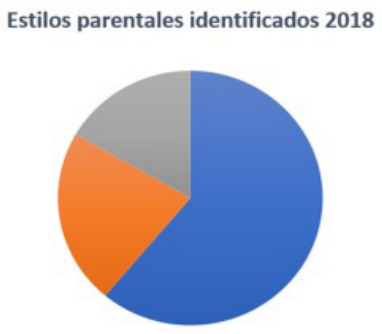

- Impulsador-reflexivo

nominador-inflexible

= Dominado-complaciente

Ilustración 2b. Caracterización EP 2018

En la Tabla 3 se presenta de manera comparativa los estilos parentales identificados en cada uno de los momentos caracterizados. La información se organiza agrupando los casos según las permanencias y transformaciones encontradas.

Tabla 3. Tabla comparativa estilos parentales identificados (2011-2018)

\begin{tabular}{|c|c|c|c|}
\hline No. & Estilo inicial (2011) & $\begin{array}{c}\text { Estilo en el Seguimiento } \\
\text { (2018) }\end{array}$ & Transformación \\
\hline Caso 2 & Dominado-complaciente & Impulsador - reflexivo & ++ \\
\hline Caso 5 & Dominado-complaciente & Dominador-inflexible & + \\
\hline Caso 13 & Dominado-complaciente & Dominado-complaciente & \\
\hline Caso 1 & Dominador-inflexible & Impulsador-reflexivo & + \\
\hline Caso 3 & Dominador-inflexible & Impulsador-reflexivo & + \\
\hline Caso 4 & Dominador-inflexible & Impulsador- reflexivo & + \\
\hline Caso 7 & Dominador - inflexible & Impulsador- reflexivo & + \\
\hline Caso 9 & Dominador - inflexible & Impulsador-reflexivo & + \\
\hline Caso 8 & Dominador-inflexible & Dominador - inflexible & \\
\hline Caso 14 & Dominador-inflexible & Dominador - inflexible & \\
\hline Caso 15 & Dominador-inflexible & Dominador - inflexible & \\
\hline Caso 17 & Dominador- inflexible & Dominado-complaciente & - \\
\hline Caso 11 & Impulsador-reflexivo & Impulsador-reflexivo & \\
\hline Caso 6 & Impulsador- reflexivo & Impulsador- reflexivo & \\
\hline Caso 10 & Impulsador-reflexivo & Impulsador-reflexivo & \\
\hline Caso 12 & Impulsador- reflexivo & Impulsador- reflexivo & \\
\hline Caso 18 & Impulsador- reflexivo & Impulsador-reflexivo & \\
\hline Caso 16 & Impulsador-reflexivo & Dominado-complaciente & -- \\
\hline
\end{tabular}

En 2018 se observa permanencia del estilo parental inicialmente identificado en 9 de los 18 casos considerados (50\%). En los otros 9 casos se detectan transformaciones. La Tabla 4, muestra el cruce entre el estilo parental incial, detectado en 2011, y el estilo parental final, identificado en 2018. 
Tabla 4. Resultados tabla cruzada caracterización de estilo parental (2011-2018) en la muestra general de 18 casos

\begin{tabular}{llcccc}
\hline & & \multicolumn{2}{c}{ Estilo parental identificado en 2018 } & \multirow{2}{*}{ Total } \\
\cline { 3 - 5 } & & $\begin{array}{c}\text { Impuldador- } \\
\text { reflexivo }\end{array}$ & $\begin{array}{c}\text { Dominador- } \\
\text { inflexible }\end{array}$ & $\begin{array}{c}\text { Dominado- } \\
\text { complaciente }\end{array}$ & \\
\hline \multirow{2}{*}{$\begin{array}{l}\text { Estilo parental } \\
\text { identificado en } \\
\mathbf{2 0 1 1}\end{array}$} & Impulsador- reflexivo & 5 & 0 & 1 & 6 \\
\hline & Dominador -inflexible & 5 & 3 & 1 & 9 \\
\hline & Total & $\mathbf{1 1}$ & $\mathbf{4}$ & 1 & 3 \\
\hline
\end{tabular}

Fuente: Elaboración propia a partir de los datos

En la Tabla 4, la diagonal (área sombreada) representa los casos de permanencia del estilo. Los casos ubicados por debajo de la diagonal, siete casos, representan transformaciones positivas, en tanto el nuevo estilo favorece en mayor medida comportamientos autónomos. Por otro lado, los dos casos situados por encima de la diagonal representan transformaciones negativas, en los que se ha variado hacia un estilo que favorece una mayor dependencia.

\section{Permanencia del estilo parental de crianza}

En nueve de los 18 casos se encuentra que el estilo parental permanece igual, en términos generales. En cinco de estos se mantuvo un estilo parental impulsador-reflexivo porque, desde el punto de vista de los participantes, les ha generado una clara ganancia en relación con su desarrollo personal y social, y con los procesos de autonomía de sus hijos, permitiéndoles perfeccionar sus capacidades y mantener un proyecto personal relativamente independiente.

En los tres casos en los que permanece el estilo parental dominador-inflexible, desde el punto de vista de los participantes, ha funcionado como mecanismo de protección, control, manejo y modificación de la conducta del hijo con discapacidad. El hijo es considerado como un "bebé", o un "niño" -así sea un joven adulto-, por lo que la función parental se centra en la vigilancia, el cuidado, la defensa y la protección. Permanece en ellos una visión de la discapacidad como un déficit y el mantenimiento de este estilo satisface sus necesidades de control. En este estilo los padres asumen un papel protagónico en la interacción y el hijo alcanza niveles básicos de autonomía en contextos cercanos (familia-escuela).

En el caso de permanencia del estilo dominado-complaciente, este ha funcionado como una forma de compensar el agravamiento de las condiciones de salud y la pérdida paulatina e irreversible de habilidades de la hija, situación ante la cual, la madre siente que no tiene control. En este caso, la niña presenta una condición de autismo severo al que posteriormente se le añade un cuadro de Mucopolisacaridosis tipo III, una enfermedad metabólica profundamente discapacitante.

\section{Transformaciones de los estilos parentales de crianza}

En nueve de los 18 casos analizados se encuentran transformaciones en los estilos parentales. Siete de ellas pueden ser entendidas como transformaciones positivas, en tanto parten de estilos más ligados al establecimiento y mantenimiento de relaciones de dependencia a estilos que propician comportamientos más autónomos. Sólo en dos casos se detecta la dirección inversa -de un estilo más favorecedor de la autonomía a otro de mayor dependencia-. Examinaremos estos nueve casos en detalle. 


\section{Transformaciones positivas}

En cinco de los nueve casos se parte de estilos inicialmente identificados como dominador-inflexible que han transitado hacia estilos del tipo impulsador-reflexivo.

El estilo dominador-inflexible está caracterizado principalmente por una figura de adultos cuidadores, protectores, sapientes y decisores. Está ligado a una visión médico-reparadora de la discapacidad, es decir, centrado en el déficit, lo que sitúa a los hijos como dominados y sometidos. Los cuidadores que presentan este de estilo de crianza lo señalan:

“...la crianza de mi hija discapacitada no es tan fácil, pero con Dios primeramente que me dio la sabiduría la fortaleza y el amor, he logrado sacarla adelante, ayudándola en cada logro que pueda tener, exigiéndole, cuidándola, protegiéndola, tomo decisiones. Mi función es velar porque siempre esté bien y tengo mucho control por su discapacidad" (caso 7, 2011)

El control del comportamiento en este tipo de estilo suele ser fuerte, tal y como se indica:

“...cuando no obedece se le corrige a veces se le pega, o grita, por su discapacidad a veces no entiende pues para criar a una persona con discapacidad hay que tener mucha paciencia" (caso 9, 2011)

Siete años más tarde, el estilo parental en la crianza de estos cinco casos se ha transformado hacia un estilo impulsador- reflexivo, en el que los padres se centran más en las habilidades que tienen los hijos que en la carencia producida por la discapacidad. Tal como se observa en los siguientes fragmentos de entrevistas realizadas en 2018:

"...mi hija es una persona muy atenta que comprende lo que se le dice, es colaborativa con las demás personas, es cariñosa y aunque tenga su dificultad de aprendizaje es muy inteligente... La inscribo en actividades que le permitan obtener un aprendizaje teniendo en cuenta que debe adquirir los conocimientos con más paciencia, pero no son inalcanzables" (caso 7, 2018).

"yo quiero que él salga adelante y yo le digo que para eso tiene que empezar a hacer las cosas solo... él ya está muy grande y yo sé que él puede..." (caso 9, 2018)

Se encuentran, además, algunas situaciones que parecen ser importantes en esta transformación del estilo. En una de ellas se puso de presente la capacidad del hijo, lo que marcó un cambio en la percepción de los padres. Como se observa en los siguientes fragmentos:

“...se ganó un premio con un compañero del colegio, en un concurso musical donde participa todo Atlántico..." (caso 1, 2018)

“... él ya trabaja, le colabora al papá en mecánica de motos, ha aprendido a salir y hacer muchas cosas él solito, se ha soltado poco a poco y eso ha resultado bien y antes siento que nos demoramos mucho en empezar a soltarlo" (caso 3, 2018)

"...es una persona que conduce carro, moto, tiene todas las facultades que, quizás, un oyente no tiene" (caso 4, 2018) 
En otro caso, se observa la generación de más estrategias parentales para la comunicación, interacción y el manejo de las particularidades de la discapacidad.

“...la crianza que se le brinda ahora es igual a mis otros hijos con los mismos valores y normas de casa, sin embargo, por su dificultad se atiende, refuerza y explica un poco más las cosas para obtener una mayor compresión de lo que se le dice..." (caso 7, 2018)

Continuando con las transformaciones positivas, se presentaron dos casos en los que el estilo parental transitó del estilo dominado-complaciente a los estilos impulsador-reflexivo (caso 2) y dominador-inflexible (caso 5), respectivamente.

El primer caso corresponde a una madre que tenía un estilo parental dominado-complaciente, es decir, se caracterizaba por el bajo control parental y un sometimiento ante las exigencias y particularidades de la discapacidad del hijo. Esta madre concebía al hijo como impulsivo y dominante y desde este punto de vista su papel era complacerlo. El siguiente fragmento refleja su sentir:

“...es un niño con dificultades, rebelde, cuando le hicieron el examen para saber que tenía el resultado fue desesperanzador, me he equivocado varias veces en su educación y tratamiento, por eso me he propuesto que mi hijo tenga todo lo que el necesita porque lo quiero hacer feliz..." (caso 2, 2011)

Otro aspecto que añadió complejidad a la situación inicial fue la condición de ser madre soltera:

“...Cuando quedé embarazada me preocupé mucho porque yo fui criada en un hogar compuesto por mis padres y mis hermanos, no concibo un hogar formado por solo por la madre... la psicóloga me decía que a mi hijo le hacía falta el cariño de su padre, esto es muy desesperanzador ya que nunca se ha criado con él, es más, no lo conoce, por problemas con su padre no pudimos entendernos y tuvimos que separarnos, el niño ha crecido con ese vacío" (caso 2, 2011)

En la segunda caracterización esta madre muestra un gran avance. Su estilo de crianza se transformó en impulsador-reflexivo, desde el que logra reconocer la habilidad del hijo, tener mayor confianza en su capacidad y tomar el control e impartir disciplina mediada por la reflexión.

"...antes lo veía con dificultad, ahora lo veo como una persona normal, con momentos de rebeldía, pero luego comprende que quiere estudiar y que quiere ser alguien en la vida, enfatizo en horario de llegada, máximo nueve de la noche, cuando va al colegio, al salir debe ir directo a la casa ..." (caso 2, 2018).

Se encuentran así, dos situaciones importantes que parecen motivar esta transformación. Primero, y como ya se había mencionado antes, la presencia de experiencias positivas que permitieron el reconocimiento de las capacidades del hijo:

"...lo veo como un profesional, como alguien relacionado con la fase deportiva y que maneja bien la psicología, trabajando en otro país..." (caso 2, 2018). 
Segundo, la reconceptualización de la situación propia, que pasa de la queja por la ruptura conyugal a la consolidación de estrategias para asumir rol paterno-materno, que le permite el empoderamiento como madre en la relación parentofilial:

“...Soy madre soltera, me toca duro, más que todo el comportamiento rebelde cuando no hace caso y no acata órdenes. Mi función es ser su madre, estar pendiente de todo, ver por él, yo tengo que decidir, preguntarle que quiere o necesita, estar pendiente de su estudio, alimentación y cosas que necesita, también que no tenga malas amistades..." (caso 2, 2018)

El segundo de los casos enunciado corresponde a una madre que se encontraba inicialmente sometida a las particularidades propias de la discapacidad y a limitaciones económicas que la obligaban a trabajar fuera de casa y dejar a su hijo con los abuelos. Esta situación parecía generarle culpa, por lo cual buscaba complacer al hijo en todo lo que pudiese. En sus palabras:

“...no ha sido fácil ya que yo trabajo y el niño con mis padres es necio, yo lo he tomado de una manera comprensiva pues se le dificulta el entendimiento... quiero que me vea como la persona que lo ama incondicionalmente." (caso 5, 2011).

Esta madre transitó al estilo dominador-inflexible, pasando, de bajo a alto control:

"...tiene su temperamento, si yo le digo tienda la cama él la tiende, no la hace por sí solo, pero si le ordeno si lo hace. Hace rato que no le pego, ahora le muestro la correa, pero no le pego, no tengo que estarlo castigando, le digo las cosas con malgenio y ahí sabe que está haciendo algo malo..." (caso 5, 2018)

De nuevo en este caso, como en el anterior, hay un inicio de tránsito hacia el reconocimiento de las capacidades del hijo:

“...no le gusta la agresividad, él pone la queja si algo le hacen, no le gusta mucho el contacto físico, solo si quiere a alguien. Es muy visual, le gusta comer, ir al cine, y los caballos. Él ha mejorado cantidades..." (caso 5, 2018)

\section{Transformaciones negativas}

En sólo dos casos se presentaron transformaciones negativas del estilo parental. En uno de ellos, se transforma de impulsador-reflexivo a dominado-complaciente. En este caso, la niña fue abandonada por sus padres desde los tres meses de edad por lo que la familia extensa (abuela, tía y prima) asumieron la función parental en la crianza. En el primer momento, la crianza se centró en la exigencia, la reflexión y el diálogo:

“...en cuanto a la crianza, ha sido tratada desde el punto de vista como una niña normal, se le exige acorde a su edad, se le habla cuando no acata ordenes, tratamos en lo posible de no pegarle, establecemos diálogos con ella, sacamos ratos libres para compartir ya que le gustan los helados y los coches para ir de paseo..." (caso 16, 2011) 
En el segundo momento, los cuidadores han transitado a un estilo de crianza dominado-complaciente,

“...agarra rabia con facilidad, como familia reconocemos que hemos sido sobreprotectores con ella y que deseamos que sea más independiente, pero tenemos el temor de que se lastime o sea agresiva cuando interactúe con otras personas..." (caso 16, 2018)

En este caso, se puede identificar que la transformación del estilo obedece a cierto sentimiento de lástima y de culpa ante situaciones adversas del contexto, en este caso relacionadas con el abandono por parte de los padres. En palabras de la tía, quien es la informante:

“...Desde muy pequeña quedó en casa de mi abuela dejada por su madre a los tres meses de nacida, para nosotros fue bastante difícil ya que no entendíamos el porqué de su condición..." (caso 16, 2018)

Esta situación además propicia que quienes ejercen la función parental, se rindan frente a comportamientos rebeldes, al no sentirse suficientemente validados como figuras de autoridad. En sus palabras:

“...la realización de las actividades es compleja porque se cansa rápido, estas actividades no son de su agrado, igual tenemos problemas para que asista a las terapias, no la disciplinamos o no hemos sido constantes con la disciplina y por eso se presentan dificultades en el comportamiento; pienso que el padre es una figura de autoridad, pero como él no está muy presente es difícil ejercer la autoridad..." (caso 16, 2018)

En este caso parece haber una cadena de delegaciones: los padres abandonan a la hija donde los abuelos, ellos delegan su manejo en la tía, y está en la prima; situación que podría propiciar un estilo dominado-distante: no hay nadie realmente implicado con la crianza, en tanto ninguna figura se siente autorizada para hacerlo.

En el segundo caso, se presenta una transformación negativa del estilo dominador-inflexible al dominado-complaciente. En este caso la madre se encontraba, en 2011, dedicada al hijo, a su terapia y a su rehabilitación. En sus palabras,

“...él es el motor de nuestra casa por eso está rodeado de mucho cariño, de parte de nosotros sus padres y sus hermanos...Me dediqué a él a su cuidado, lo he tenido en (muchas instituciones) para mejorar sus habilidades. Se le exige mucho, se le hace bastante terapia obligando al cuerpo a ejercitarse y a hacer. Dejé de trabajar tres años para estar varios dedicada exclusivamente a él..." (caso 17, 2011).

En el año 2018, la madre presenta una visión totalmente distinta de la experiencia de crianza:

“... él es un niño que no ha tenido ninguna evolución desde que salió de la clínica cuando le dio la parálisis, es como tener un bebé recién nacido, toca darle de comer uno, lo cambia de posición, se le hace el aseo, pero nunca presentó evolución. No habla nada, su comunicación es solo por el llanto, cuando le duele algo o tiene ganas de algo llora y uno ya lo reconoce. Incluso 
En general, los resultados ratifican una tendencia hacia la permanencia del estilo parental, tal y como ha sido definido por Manjarrés y Hederich (2018), y en particular en los casos en que este estilo ha mostrado una funcionalidad significativa. De los 18 casos examinados, nueve mantuvieron su estilo parental. no ha crecido casi nada para el tamaño de una persona de 18 años. Yo le hablo harto, lo consiento, lo alzo, le doy la comida, le cambio el pañal, estoy dos horas con él..." (caso 17, 2018).

Se identifican dos explicaciones para esta transformación. Primero, la ocurrencia de un evento adverso, relacionado con una luxación de cadera del hijo provocada por la terapia misma. Esto llena a la madre de culpa, al considerarse responsable por sobre-exigirle:

“...en vez de mejorar, empeoró, cogió más rigidez en los músculos y esto tuvo efectos contrarios, tuvo luxación de cadera. Al principio no era espástico, pero entre más terapias le hacíamos, cogía más espasticidad y se volvía más rígido..." (caso 17, 2018)

Esto se acentúa por la percepción de ausencia de mejoría en el hijo:

“...nosotros antes le mandamos a hacer terapias, pero nunca se le vio la mejoría. Movimientos ningunos, de que movió la cabeza, que haya intentado gatear, nada, se quedó su desarrollo prácticamente en los 15 días de nacido. Es dependiente totalmente de que uno le haga todo, tiene una camita de hospital y como uno lo deja en la posición queda quietico, no habla ni nada, hasta que lo volteemos..." (caso 17, 2018)

Segundo, el cambio de la estructura familiar con la llegada de nuevos miembros que requieren atención y la prioridad de responder a las necesidades de otros miembros de la familia y de la realización personal:

"Nació un hijo después de él y tuve que trabajar para sacar a mis otros hijos adelante. A él, tenerlo aquí en la casa, cuidarlo y darle la mejor calidad de vida, porque no se le ve cambio ni positivo ni negativo si tiene terapia..."

"a veces uno se exige demasiado de que las cosas estén saliendo mal, pero uno debe tener en cuenta que hay otras cosas en la vida que se deben hacer, la vida sigue corriendo, no estoy aportando en la casa y no ejercía la carrera que estudié, entonces tomé la decisión de trabajar..." (caso 17, 2018).

\section{Discusión}

El objetivo del presente estudio fue establecer las permanencias y las transformaciones de los estilos parentales de crianza de padres o cuidadores permanentes de hijos con discapacidad en dos momentos diferenciados por siete años e identificar posibles explicaciones.

En general, los resultados ratifican una tendencia hacia la permanencia del estilo parental, tal y como ha sido definido por Manjarrés y Hederich (2018), y en particular en los casos en que este estilo ha mostrado una funcionalidad significativa. De los 18 casos examinados, nueve mantuvieron su estilo parental.

Esta tendencia a la permanencia del estilo parental, sin embargo, aunque no niega de plano lo mencionado por Harris (2002) y Torío, Peña y Rodríguez (2008) frente a la variabilidad que puede tener el estilo parental cuando es permeado por diversas circunstancias durante la trayectoria vital, sí les impone límites y cierta dirección a las 
Pág 77

Tanto en los casos de permanencia como en los de transformaciones positivas de los estilos parentales que favorecen el desarrollo de la autonomía de los hijos con discapacidad, los padres se enfocan a la visión optimista dirigida a la organización, reestructuración de pensamiento, el crecimiento personal y la oportunidad de aprendizaje, que se sobrepone a los sentimientos de angustia o estrés parental. transformaciones. En efecto, de los nueve casos en que se detectaron transformaciones importantes en los estilos parentales, en siete se observan transformaciones que hemos llamado positivas, en el sentido en que van en la dirección de procurar mayor autonomía al hijo con discapacidad, y solo en dos casos se observan transformaciones en el sentido contrario; esto también ratifica lo planteado por el MEPD respecto a que cuando el estilo se transforma la tendencia es a mejorar en pro del favorecimiento de la autonomía del hijo.

De acuerdo con los relatos de los participantes del presente estudio, los casos de permanencia del estilo parental impulsador-reflexivo se explican por la funcionalidad que dicho estilo les ha representado para el desarrollo de capacidades y habilidades de los hijos. En los que se mantiene el estilo dominador-inflexible se entienden en tanto este estilo se plantea como mecanismo de control y modificación de la conducta del hijo que reduce la ansiedad y el estrés parental. Y el único caso en el que se mantiene el estilo dominado-complaciente, se perpetúa como forma de compensación de las dificultades percibidas y comprendidas por los padres como resultados de sus acciones pasadas que desencadenan sentimientos de culpa. Estos hallazgos permiten sugerir que los estilos parentales de crianza que favorecen en mayor medida la autonomía de los hijos con discapacidad son aquellos en donde se observa mayor permanencia del mismo.

Los resultados reiteran los postulados de Baumrind $(1971,1991,1996,2005)$ verificados y desarrollados por Darling y Steinberg (1993), Maccoby y Martin (1983) y Musitu y Cava (2001), frente a la influencia de los estilos parentales en el desarrollo de la autonomía del hijo; y apoyan la tendencia actual de estudios sobre "crianza positiva y saludable" o "crianza negativa", como formas de examinar la calidad de la interacción parentofilial en términos de potenciación del desarrollo (Bernal \& Sandoval, 2013; Capano \& Ubach, 2013; Martínez \& Becedóniz, 2009; Morales, Martínez. Nieto, \& Lira, 2017; Suárez, Byrne, \& Rodrigo, 2016). En esta línea, en el campo de la discapacidad, estudios como los de Aran, Shalev, Biran y Gross-Tsur, (2007), Gau, Chiu, Soong, Lee (2008) y Fuenzalida y Brun (2017), profundizan en la influencia del estilo parental en la autonomía, independencia y calidad de vida de las personas con discapacidad y estudios como el de Tellegen y Sanders (2013), se centran en la crianza positiva en casos de personas con discapacidad.

En la mitad de los casos analizados se encuentran transformaciones en los estilos parentales de crianza; de los cuales la mayoría son entendidas como transformaciones positivas en tanto propician comportamientos más autónomos de los hijos con discapacidad, y además se constata su relación con eventos puntuales que hacen visibles, a la mirada parental, nuevas capacidades en los hijos. Estos eventos conllevan una transformación de las creencias sobre la discapacidad específica, que terminan permeando las prácticas de relación y las pautas de crianza.

Tanto en los casos de permanencia como en los de transformaciones positivas de los estilos parentales que favorecen el desarrollo de la autonomía de los hijos con discapacidad, los padres se enfocan a la visión optimista dirigida a la organización, reestructuración de pensamiento, el crecimiento personal y la oportunidad de aprendizaje, que se sobrepone a los sentimientos de angustia o estrés parental. Los relatos presentados por los cuidadores relacionan estos procesos de adaptación positiva con aspectos abordados en estudios como la resiliencia (Huerta \& Rivera, 2017; Ocampo \& Vargas, 2018; Roque \& Acle, 2013) el bienestar, la esperanza y la espiritualidad (Ekas, Whitman, \& Shivers, 2009; Femenias \& Sánchez, 2003; Lu, Wang, Lei, Shi, Zhu, \& Jiang. 
Pág 78

Tanto en los casos de permanencia como en los de transformaciones negativas de estilos parentales de crianza que conllevan a la dependencia continuada de los hijos con discapacidad, se advierte, en las situaciones narradas por los participantes, la intersección y priorización de aspectos emocionales relacionados con el estrés, la ansiedad, la depresión y la angustia parental.
2018; Shenaar-Golan, 2016), las estrategias de afrontamiento como mediadoras para el ajuste parental (Dardas \& Ahmad, 2015; Glidden \& Natcher, 2009; Herrera, 2015; Losada \& Baña, 2017; Twoy, Connolly, \& Novak, 2007; Woodman \& Hauser-Cram, 2013) y la importancia del soporte o apoyo social en el proceso (Benson, 2012; Findler, Klein Jacoby, \& Gabis, 2016; Hsiao, 2014; Lu, Wang, Lei, Shi, Zhu, \& Jiang, 2018). Estos aspectos median en la consolidación del estilo parental, el funcionamiento familiar y la calidad de vida.

Por otra parte, las transformaciones negativas en los estilos parentales de crianza de personas con discapacidad, en el sentido que no propician el desarrollo de su autonomía, pueden atribuirse a una combinación de circunstancias desfavorables. Se identifica, en los relatos, que la falta de mejoría o avance del hijo durante su trayectoria vital unida a situaciones de manejo inicial equivocado que reforzaron la dependencia excesiva y continuada, y generaron problemas comportamentales, motivaron que el estilo parental de crianza se transformara negativamente, por su imposibilidad de aportar al desarrollo.

Tanto en los casos de permanencia como en los de transformaciones negativas de estilos parentales de crianza que conllevan a la dependencia continuada de los hijos con discapacidad, se advierte, en las situaciones narradas por los participantes, la intersección y priorización de aspectos emocionales relacionados con el estrés, la ansiedad, la depresión y la angustia parental. Otros estudios han analizado la influencia de estos aspectos en el ejercicio de la función parental (Baker, Seltzer, \& Greenberg, 2011; Durán, García, Fernández, \& Sanjurjo, 2016; Jean, Mazlan, Ahmad, \& Maamor, 2018; Jess, Totsika, \& Hastings, 2018; Mitchell, Szczerepa, \& Hauser-Cram, 2016; Phillips, Conners, \& Curtner-Smith, 2017; Woolfson \& Grant, 2006; entre otros).

Estos hallazgos apoyan la importancia de hacer visibles las capacidades de los niños y jóvenes con discapacidad, en tanto esta visibilidad es una condición necesaria para la transformación de los estilos parentales hacia otros que favorezcan la autonomía.

\section{Alcances y limitaciones}

Este estudio permite aportar a la comprensión de la crianza de personas con discapacidad y al estudio de los estilos parentales allí presentes, a partir de análisis situados y estudios longitudinales que permitan examinar las prácticas educativas paternas transcurridos diferentes momentos de la trayectoria vital de sus hijos. Estos estudios no son frecuentes, por lo que esta oportunidad se convierte en un ejercicio que permite identificar variables que pueden motivar permanencias o transformaciones. Estas variables, se convierten en campos de acción para el fortalecimiento de la labor educativa parental, los cuales deben seguir siendo estudiados ampliando las investigaciones de seguimiento que permitan corroborarlos y validarlos.

Dentro de las limitaciones del estudio, debe mencionarse que la característica de auto selección de la muestra final, condición indispensable del estudio, al tiempo que limita el tamaño y la generalidad, introduce un sesgo en los resultados al disminuir la posibilidad de que se presenten familias con estilo dominado-distante. Esto podría ser controlado introduciendo, en proyecto futuros, estímulos adicionales a la participación en el estudio. 


\section{Referencias}

Acosta-Muñoz, J., Toro-Ibarra, A., \& Guerrero-Ramírez, M. (2015). Estilos parentales de enseñanza en familias con niños con necesidades educativas especiales en Samacá-Boyacá. Praxis, 11(1), 19-29. doi: http://dx.doi.org/10.21676/23897856.1550

Aguirre, E., \& Castro, C. (2007). La crianza en el proceso de inclusión social de niños con déficit sensoriomotor. Conferencia: $5^{\circ}$ reunión "Escenarios de la diversidad: pasado y presente" del grupo de trabajo: familia e infancia de CLACSO. México.

Aran, A., Shalev, R., Biran, G., \& Gross-Tsur, V. (2007). Parenting style impacts on quality of life in children with cerebral palsy. Journal of pediatrics, 151(1), 56-60. doi: http://dx.doi.org/10.1016/i.jpeds.2007.02.011

Aroca, C., \& Cánovas, P. (2012). Los estilos educativos parentales desde los modelos interactivos y de construcción conjunta: revisión de las investigaciones. Teoría de la Educación: Revista Interuniversitaria, 24(2), 149-176.

Baker J., Seltzer M., \& Greenberg J. (2011). Longitudinal effects of adaptability on behavior problems and maternal depression in families of adolescents with autism. Journal of Family Psychology, 25(4),601-609. doi: http://dx.doi.org/10.1037/ a0024409

Baumrind, D. (1971). Current patterns of parental authority. Developmental Psychology, 4(1), 1-103. doi: http://dx.doi.org/10.1037/h0030372

Baumrind, D. (1991). The influence of parenting style on adolescent competence and substance use. The Journal of Early Adolescence, 11(1), 56-95. doi: http://dx.doi. org/10.1177/0272431691111004

Baumrind, D. (1996). The discipline controversy revisited. Family Relations: An Interdisciplinary Journal of Applied Family Studies, 45(4), 405-414. doi: http://dx.doi. org/10.2307/585170

Baumrind, D. (2005). Patterns of parental authority and adolescent autonomy. New Directions for Child and Adolescent Development, (108), 61-69. doi: http://dx.doi. org/10.1002/cd.128.

Benson, P. (2012). Network characteristics perceived social support, and psychological adjustment in mothers of children with autism spectrum disorder. Journal of Autism and Developmental Disorders, 42(12), 2597-2610. doi: http://dx.doi. org/10.1007/s10803-012-1517-9

Bernal-Martínez, A., \& Sandoval-Estupiñan, L. (2013). "Parentalidad positiva" o ser padres y madres en la educación familiar". ESE. Estudios sobre Educación, 25, 133-149. http://hdl.handle.net/10171/34728

Cámara, Á., \& López, J. (2014). Estilos de educación en el ámbito familiar. REOP - Revista Española de Orientación y Psicopedagogía, 22(3), 257-276. doi: 10.5944/reop. vol.22.num.3.2011.11280.

Capano, A., \& Ubach, A. (2013). Estilos parentales, parentalidad positiva y formación de padres. Ciencias Psicológicas, 7(1), 83-95. http://www.scielo.edu.uy/scielo. php?script=sci arttext\&pid=S1688-42212013000100008\&lng=es\&tlng=es

Coloma, J. (1993). Estilos educativos paternos. En Quintana, J. (coord.). Pedagogía familiar (pp. 45-58). Madrid: Narcea.

Dardas, L., \& Ahmad, M. (2015). For fathers raising children with autism, do coping strategies mediate or moderate the relationship between parenting stress and quality of life?. Research in Developmental Disabilities, 36, 620-629. doi: http:// dx.doi.org/10.1016/j.ridd.2014.10.047

Darling, N., \& Steinberg, L. (1993). Parenting style as context: An integrative model. Psychological Bulletin, 113(3), 487-496. doi: http://dx.doi. org/10.1037/00332909.113.3.487 
Díaz, M., \& Mejía, C. (2015). Estrategias parentales y discapacidad auditiva: su relación con la asunción de la maternidad. Quaderns de Psicologia, 17(2), 63-73. doi: http://dx.doi.org/10.5565/rev/qpsicologia.1245

Durán, M., García-Fernández, M., Fernández, J., \& Sanjurjo, B. (2016). Afrontamiento, estrés parental y calidad de vida de los cuidadores principales de personas TEA. Revista De Estudios E Investigación En Psicología Y Educación, 3(1), 60-68. doi: http://dx.doi.org/10.17979/reipe.2016.3.1.1749

Ekas, N., Whitman, T., \& Shivers, C. (2009). Religiosity, spirituality, and socioemotional functioning in mothers of children with autism spectrum disorder. Journal of Autism and Developmental Disorders, 39(5), 706-719. doi: http://dx.doi.org/10.1007/ s10803-008-0673-4

Femenias, M., \& Sánchez, J. M. (2003). Satisfacción familiar, bienestar psicológico y ansiedad en parejas con hijos con necesidades educativas especiales. Siglo Cero 34(207), 19-28. https://sid.usal.es/idocs/F8/ART6709/articulos2.pdf

Findler, L., Klein Jacoby, A., \& Gabis, L. (2016). Subjective happiness among mothers of children with disabilities: The role of stress, attachment, guilt and social support. Research in Developmental Disabilities, 55, 44-54. doi: http://dx.doi.org/10.1016/j. ridd.2016.03.006

Fuenzalida-Ríos, I., Penelo, E., \& Brun-Gasca, C. (2017). Estilos educativos y psicopatología en niños y adolescentes con discapacidad intelectual de Chile y España. Quaderns De Psicologia, 19(1), 101-112. doi: http://dx.doi.org/0.5565/rev/qpsicologia.1389

Gau, S., Chiu, Y., Soong, W., \& Lee, M. (2008). Parental characteristics, parenting style, and behavioral problems among chinese children with Down syndrome, their siblings and controls in Taiwan. Journal of the Formosan Medical Association, 107(9), 693-703. doi: http://dx.doi.org/10.1016/S0929-6646(08)60114-X

Glidden, L., \& Natcher, A. (2009). Coping strategy use, personality, and adjustment of parents rearing children with developmental disabilities. Journal of Intellectual Disability Research, 53(12), 998-1013. doi: http://dx.doi.org/10.1111/j.13652788.2009.01217.x

Harris, JR. (2002). El mito de la educación. Barcelona, Grupo Editorial Random House Mondadori.

Herrera, A. (2015). Narrativas de Madres acerca de las concepciones y prácticas del cuidado en la primera infancia con discapacidad y su incidencia en la calidad de vida en la localidad de San Cristóbal. Revista CIFE: Lecturas de Economía Social, 17(26). 109-148. https://dialnet.unirioja.es/servlet/articulo?codigo=5586863

Hsiao, Y., Higgins, K., Pierce, T., Whitby, P., \& Tandy, R. (2017). Parental stress, family quality of life, and family-teacher partnerships: Families of children with autism spectrum disorder. Research in Developmental Disabilities, 70, 152-162. doi: http://dx.doi.org/10.1016/j.ridd.2017.08.013

Huerta, Y., \& Rivera, M. (2017). Resiliencia, recursos familiares y espirituales en cuidadores de niños con discapacidad. Journal of Behavior, Health \& Social, 9(2),70-81. doi: http://dx.doi.org/10.1016/j.jbhsi.2018.01.005

Isaza-Valencia, L., \& Henao-López, C. (2012). Influencia del clima sociofamiliar y estilos de interacción parental sobre el desarrollo de habilidades sociales en niños y niñas. Persona, 0(015), 253-271. doi: 10.26439/persona2012.n015.138.

Jean, Y., Mazlan, R., Ahmad, M., \& Maamor, N. (2018). Parenting Stress and Maternal Coherence: Mothers with Deaf or Hard-of-Hearing Children. American Journal of Audiology, 27(3), 260-271. doi: http://dx.doi.org/10.1044/2018_AJA-17-0093

Jess, M., Totsika, V., \& Hastings, R. (2018). Maternal Stress and the Functions of Positivity in Mothers of Children with Intellectual Disability. Journal of Child and Family Studies, 27(11), 3753-3763. doi: http://dx.doi.org/10.1007/s10826-018-1186-1 
Losada-Puente, L., \& Baña-Castro, M. (2017). Calidad de vida del alumnado con alteraciones del desarrollo individual: Apoyos familiares desde la perspectiva profesional. Revista de Estudios e Investigación en Psicología y Educación, Extra-11, 1-5. doi: http://dx.doi.org/10.17979/reipe.2017.0.11.2112

Lu, M., Wang, G., Lei H., Shi, M., Zhu, R., \& Jiang, F. (2018). Social Support as Mediator and Moderator of the Relationship Between Parenting Stress and Life Satisfaction Among the Chinese Parents of Children with ASD. Journal of Autism and Developmental Disorders, 48(4), 1181-1188. doi: http://dx.doi.org/10.1007/s10803-017$\underline{3448-y}$

Maccoby, E., \& Martin, J. (1983). Socialization in the context of the family: Parent-child interaction. En Mussen, P. H. (Ed. de la serie) \& Hetherington, E. M. (Ed. del volumen), Handbook of Child Psychology, 4, 1-101). Nueva York: Wiley.

Manjarrés, D., \& Hederich, C. (2018). Estilos parentales en la discapacidad. Examen de la evidencia empírica sobre un modelo. Revista Latinoamericana de Psicología (50), 3, 187-200. doi: http://dx.doi.org/10.14349/rlp.2018.v50.n3.6

Manjarrés, D., León, E., Martínez, R., \& Gaitán, A. (2011). Familia y Discapacidad, retos y desafíos para la educación. Fase 1 dinámicas generadas al interior del núcleo familiar de las personas con discapacidad: pautas de crianza. Centro de investigación Universidad Pedagógica Nacional- Fundación Universitaria Monserrate.

Manjarrés, D. (2012). Apoyo y fortalecimiento a familias para la crianza de niños y niñas con discapacidad. Horizontes Pedagógicos, 14(1), 97-118.

Martínez, R., \& Becedóniz, C. (2009). Orientación Educativa para la Vida Familiar como Medida de Apoyo para el Desempeño de la Parentalidad Positiva. Psychosocial Intervention, 18 (2), 97-112. http://scielo.isciii.es/scielo.php?script=sci arttext\&pid=S1132-05592009000200002\&lng=es

Mazzucchelli, T., Hodges, J., Kane, R., Sofronoff, K., Sanders, M., Einfeld, S., ... Gray, K. (2018). Parenting and family adjustment scales (PAFAS): validation of a brief parent-report measure for use with families who have a child with a developmental disability. Research in Developmental Disabilities, (72), 140-151. doi: http://dx.doi.org/10.1016/j. ridd.2017.10.011

Mestre, V. (2014). Desarrollo prosocial: crianza y escuela. Revista Mexicana de Investigación en Psicología, 6(2), 115-134. https://pdfs.semanticscholar.org/d362/c3d46917ede116ebf78cc52d48a0c3d9703a.pdf

Mitchell, D., Szczerepa, A., \& Hauser-Cram, P. (2016). Spilling over: Partner parenting stress as a predictor of family cohesion in parents of adolescents with developmental disabilities. Research in Developmental Disabilities, 49-50, 258-267. doi: https://doi.org/10.1016/j.ridd.2015.12.007

Montoya-Castilla, I., Prado-Gascó, V., Villanueva-Badenes, L., \& González-Barrón, R. (2016). Adaptación en la infancia: influencia del estilo parental y del estado de ánimo. Acción Psicológica, 13(2), 15-30. doi: https://doi.org/10.5944/ap.13.2.17807

Morales, S., Martínez, M., Nieto, J., \& Lira, J. (2017). Crianza positiva y negativa asociada a los problemas severos de conducta infantil. Salud y drogas, 17(2), 137-149. https://dialnet.unirioja.es/servlet/articulo?codigo $=6106502$

Murillo-Casas, Á., Priegue-Caamaño, D., \& Cambeiro-Lourido, M. (2015). Una aproximación a los estilos educativos parentales como prácticas socializadoras. Revista De Estudios E Investigación En Psicología Y Educación, (05), 083-087. doi: https://doi. org/10.17979/reipe.2015.0.05.274

Musitu, G., \& Cava, M. J. (2001). La familia y la educación. Barcelona: Ediciones Octaedro.

Ocampo, L., \& Vargas Algarin, F. (2018). Resiliencia en familias de personas con Síndrome de Down en San Pedro del Paraná, Paraguay. Revista Científica Estudios e Investigaciones, 6, 130-132. doi: https://doi.org/10.26885/rcei.foro.2017.130 
Ortega, P., Salguero, A., \& Garrido, A. (2007). Discapacidad: paternidad y cambios familiares. Avances en Psicología Latinoamericana, 25(1), 118-125. http://www.scielo.org. co/scielo.php?pid=S1794-47242007000100011\&script=sci abstract\&tlng=pt

Pinto, C., Sangüesa, P., \& Silva, G. (2012). Competencias parentales: una visión integrada de enfoques teóricos y metodológicos. Poiésis, 12(24). doi: https://doi. org/10.21501/16920945.514

Phillips, B., Conners, F., \& Curtner-Smith, M. (2017). Parenting children with down syndrome: An analysis of parenting styles, parenting dimensions, and parental stress. Research in Developmental Disabilities, 68, 9-19. doi: https://doi.org/10.1016/j. ridd. 2017.06 .010

Rapin, I., (2007). Children with Cerebral Palsy Assess Their Parents' Influence on the Quality of Their Lives: Implications for Intervention. The Journal of Pediatrics, 151(1), 7-9. doi: https://doi.org/10.1016/j.jpeds.2007.03.039

Rodríguez, M., \& Guerrero, C. (2012). La familia como promotora de la independencia en niños y niñas con discapacidad motora. Revista Electrónica Educare, 16(1), 99-111. https://dialnet.unirioja.es/servlet/articulo?codigo=3975794

Roque, M., \& Acle, G. (2013). Resiliencia materna, funcionamiento familiar y discapacidad intelectual de los hijos en un contexto marginado. Universitas Psychologica, 12(3), 811-820. doi: https://doi.org/10.11144/Javeriana.upsy12-3.rmff

Shenaar-Golan, V. (2015). Hope and subjective well-being among parents of children with special needs. Child and Family Social Work, 22(1), 306-316. doi: https://doi. org/10.1111/cfs.12241

Shenaar-Golan. V. (2016). The Subjective Well-Being of Parents of Children with Developmental Disabilities: The Role of Hope as Predictor and Fosterer of Well-Being. Journal of Social Work in Disability \& Rehabilitation, 15(2), 77-95. doi: https://doi. org/10.1080/1536710X.2016.1162119

Suárez, A., Byrne, S., \& Rodrigo, M. (2016). Validación de la Escala de Parentalidad Positiva (EPP) para evaluar programas presenciales y online de apoyo. Revista De Estudios E Investigación En Psicología Y Educación, 3(2), 112-120. doi: https:// doi.org/10.17979/reipe.2016.3.2.1883

Tellegen, C., \& Sanders, M. (2013). Stepping Stones Triple P-Positive Parenting Program for children with disability: a systematic review and meta-analysis. Research in Developmental Disabilities, 34(5), 1556-1571. doi: https://doi.org/10.1016/j. ridd.2013.01.022

Torío, S., Peña, J., \& Rodríguez, M., (2008). Estilos educativos parentales revisión bibliográfica y reformulación teórica. Revista Interuniversitaria Teoría de la Educación, (20) pp. 151-178. https://revistas.usal.es/index.php/1130-3743/article/ view/988

Twoy, R., Connolly, P., \& Novak, J. (2007). Coping strategies used by parents of children with autism. Journal of the American Academy of Nurse Practitioners 19(5), 251-60. doi: https://doi.org/10.1111/j.1745-7599.2007.00222.x

Universidad Pedagógica Nacional (2018). Resolución 1642 de 18 diciembre de 2018, por la cual se derogan las Resoluciones Nº546 de 2015 y No 1804 de 2016, y se reglamenta el Comité de Ética en Investigación. Bogotá. Colombia.

Vived, E. (2011). Habilidades sociales, autonomía personal y autorregulación. España: Prensas universitarias de Zaragoza.

Woodman, A., \& Hauser-Cram, P. (2013). The role of coping strategies in predicting change in parenting efficacy and depressive symptoms among mothers of adolescents with developmental disabilities. Journal of Intellectual Disability Research, 57(6), 513-30. doi: https://doi.org/10.1111/j.1365-2788.2012.01555.x 
Woolfson, L., \& Grant, E. (2006). Authoritative parenting and parental stress in parents of pre-school and older children with developmental disabilities. Child: Care, Health and Development, 32(2), 177-184. doi: https://doi.org/10.1111/j.13652214.2006.00603.x

Yotyodying, S., \& Wild, E. (2016). Predictors of the quantity and different qualities of home-based parental involvement: Evidence from parents of children with learning disabilities. Learning and Individual Differences, 49, 74-84. doi: https:// doi.org/10.1016/j.lindif.2016.05.003

Zuliani, L., Bastidas, M., Ariza, G., \& Giraldo, A. (2015). La experiencia paterna y su cambio de la cotidianidad en la crianza del hijo con síndrome de Down. Medellín-Colombia 2013. Archivos Venezolanos de Puericultura y Pediatría, 78(3), 82-90. 


\section{Anexo 1. Encuesta para el seguimiento a los 18 casos de la muestra}

Objetivo: Este instrumento busca obtener nueva información sobre el proceso de crianza de su hijo con discapacidad en los últimos siete años (2011-2018), con el fin de continuar profundizando en la caracterización, comprensión y la búsqueda de necesidades y requerimientos de apoyo para el desempeño de la función parental.

\section{Datos de identificación}

Fecha: Municipio /ciudad:

Nombre del informante

Parentesco: Género: M

Edad:

Tiempo que ha vivido con la persona con discapacidad:

Ocupación:

Nombre del hijo con discapacidad:

Edad: Género: M F

Tipo de discapacidad:

Cognitiva Visual Auditiva Motriz Autismo Otra: ¿cuál?

Número de Hermanos: __ Lugar que ocupa entre los hermanos

Programas de atención que recibe actualmente:

\section{Preguntas de seguimiento al proceso de crianza}

1. ¿Cómo describe usted a su hijo con discapacidad?

2. ¿Cómo ha sido la crianza de su hijo con discapacidad en estos últimos seis años?

3. ¿Qué papel cumple su hijo dentro la familia?

4. ¿Cuál cree usted que es su función como adulto frente a la crianza de su hijo con discapacidad?

5. ¿Qué normas o reglas enfatiza usted en su hijo?

6. ¿Qué valores ha formado usted en su hijo?

7. ¿De qué forma le brinda apoyo a su hijo?

8. ¿Cómo realiza el acompañamiento a su hijo durante la crianza?

9. ¿De qué manera demuestra afecto a su hijo?

10. ¿Disciplina a su hijo? ¿De qué manera?

11. ¿Qué actividades desarrolla cotidianamente con su hijo? ¿Cuáles son las más importantes?

12. ¿Su hijo realiza actividades de dispersión y disfrute? SI $\square$ NO $\square$

13. ¿Cuáles?

14. ¿Qué logros ha tenido?

15. ¿Qué desafíos tiene? ¿Cuál es el siguiente objetivo?

16. ¿A dónde cree que va a llegar? 